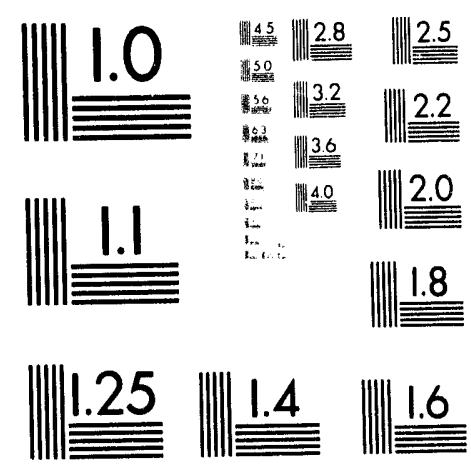



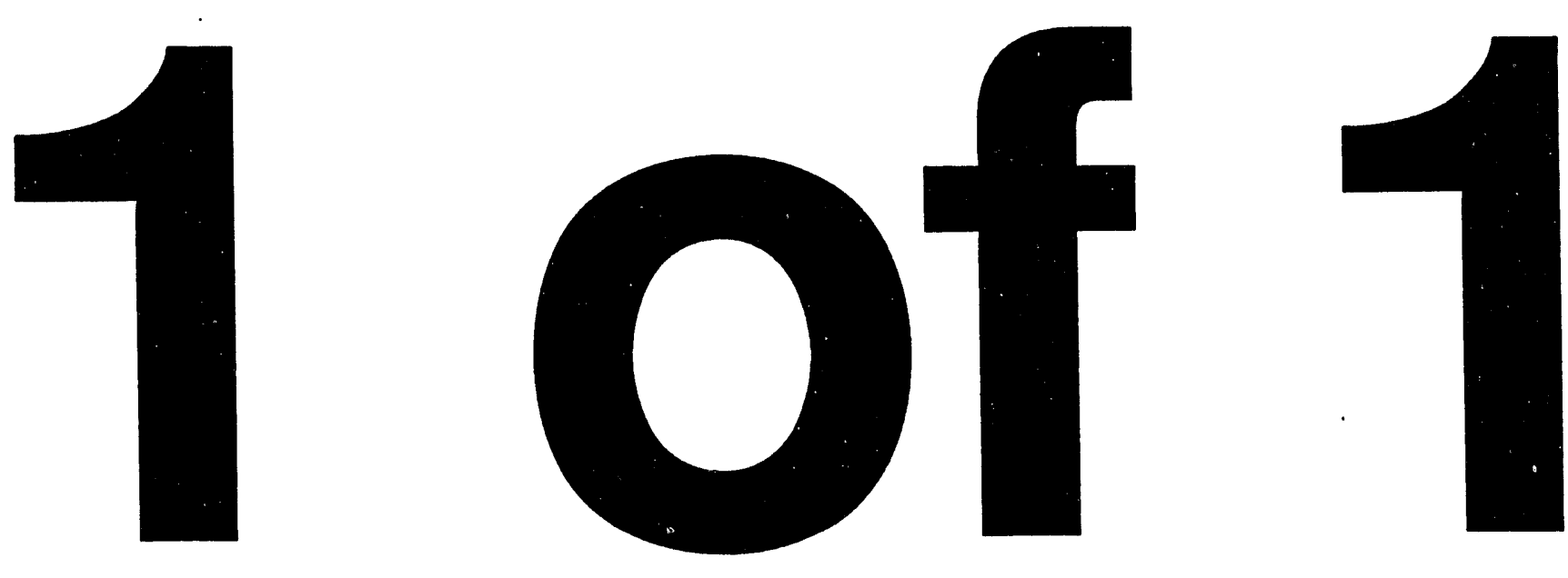
GA-A21485

\title{
A ROBUST \\ HELIUM-COOLED SHIELD/BLANKET DESIGN FOR ITER
}

\author{
by \\ C.P.C. WONG, R.F. BOURQUE, C.B. BAXI, A.P. COLLERAINE, H.J. GRUNLOH, \\ T. LETCHENBERG, J.A. LEUER, E.E. REIS, K. REDLER, R. WILL \\ V. DELBENE, S.B. INAMATI, D.D. KAPICH, J.A. KISSINGER, A.C. LEWIS, \\ J.L. PICKERING, R. RAO, R.H. RYDER, R.W. SCHLEICHER
}

This is a preprint of a paper to be presented at the 15th IEEE/NPSS Symposium on Fusion Engineering, October 11-15, 1993, in Hyannis, Massachusetts, and to be printed in the Proceedings.

Work supported by

U.S. Department of Energy

Contract DE-AC03-89ER51114

GENERAL ATOMICS PROJECT 3969

NOVEMBER 1993

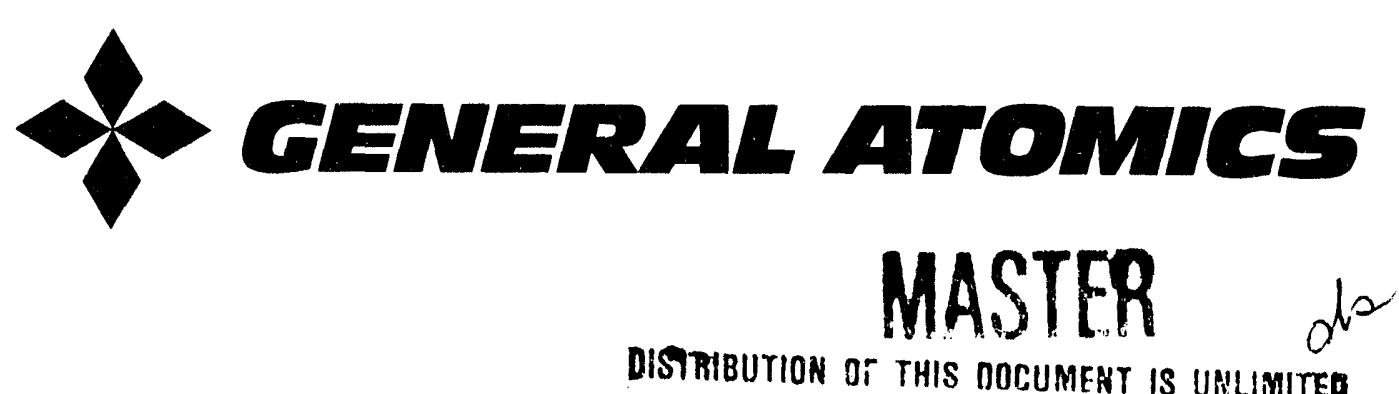




\title{
A ROBUST HELIUM-COOLED SHIELD/BLANKET DESIGN FOR ITER
}

\author{
C.P.C. Wong, R.F. Pourque, C.B. Baxi, A.P. Colleraine, H.J. Grunloh, T. Lechtenberg, J.A. Leuer, \\ E.E. Reis, K. Redler, R. Will, V. DelBene, S.B. Inamati, D.D. Kapich, J.A. Kissinger, A.C. Lewis, \\ J.L. Pickering, R. Rao, R.H. Ryder, R.W. Schleicher \\ General Atomics \\ P.0. Box 85608, San Diego, California 92186-9784
}

\begin{abstract}
General Atomics Fusion and Reactor Groups have completed a helium-cooled, conceptual shield/blanket design for ITER. The configuration selected is a pressurized tubes design embedded in radially oriented plates. This plate can be made from ferritic steel or from V-alloy. Helium leakage to the plasma chamber is eliminated by conservative, redundant design and proper quality control and inspection programs. High helium pressure at $18 \mathrm{MPa}$ is used to reduce pressure drop and enhance heat transfer. This high gas pressure is believed practical when confined in small diameter tubes. Ample industrial experience exists for safe high gas pressure operations. Inboard shield design is highlighted in this study since the allowable void fraction is more limited. Lithium is used as the thermal contacting medium and for tritium breeding, its safety concerns are minimized by a modular, low inventory design that requires no circulation of the liquid metal for the purpose of heat removal. This design is robust, conservative, reliable, and meets all design goals and requirements. It can also be built with present-day technology.
\end{abstract}

\section{INTRODUCTION}

Since the early 1950s, magnetic fusion has been developed for the principle goal of economic power production. Different helium-cooled blanket concepts were put together to address the design issues of helium pressure, heat transfer, and neutronics while concurrently meeting all material design limits. All the designs so far have a single boundary separating the helium and the vacuum chamber. The questions of potential helium leakage and reliability was not fully addressed. As we are beginning to design long burn D-T machines like the International Thermonuclear Experimental Reactor (ITER), a desire for large design margins has prompted consideration of robust design options. In order to address the requirements of high reliability and ease of fabrication based on present day technology of helium-cooled shield/blanket, a new concept was conceived, developed and proposed for ITER. This paper will present this new shield/blanket design.

\section{KEY DESIGN GOALS AND GUIDELINES}

In order to come up with a large margin design for ITER, we reviewed what is required for a robust shield/blanket, that can be built with present-day technology. To guide the GA design team to focus our effort, we derived a set of design gnals and guidelines which are listed in the following:

1. No helium leak to the plasma.

2. All pipe joints outside of the vacuum vessel.

3. A minimum of two barriers between helium and vacuum.

4. Top access for all installation/service lines.

5. Leaks in the first helium barrier must be easily detectable.

6. Design to ASME Class 1 high temperature code case $\mathrm{N} 47$, fission reactor fluence induced swelling, and other special considerations.

7. Design meets all material allowable temperatures and stress limits.

8. Full volumetric inspection of critical items.

9. Minimize inboard void fraction.

10. First wall temperature $>300^{\circ} \mathrm{C}$.

11. Configuration matches ITER machine envelope and maintenance scenario.

12. Structure exposed to plasma must take $1.2 \mathrm{MPa}$ disruption loads.

13. In case of catastrophic event, major helium leakage will not endanger ITER machine viability and public safety.

14. Credible technology that can be built by industry today.

Based on these design goals and guidelines, we put together the pressurized tube radially oriented plate design which is illustrated in Fig. 1. As an example for the derivation of the above guidelines, there are three reasons to impose the $300^{\circ} \mathrm{C}$ first wall temperature. First, this temperature was requested by the ITER-Joint Central Team (JCT) to control 


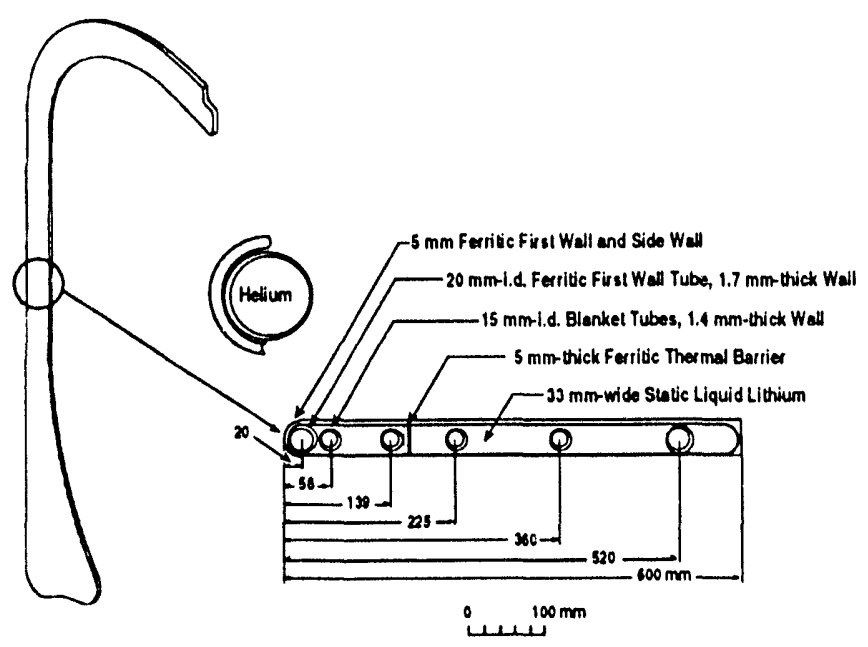

Fig. 1. Proposed ITER shield/blanket inboard plate.

the cleanliness of the first wall. Second, it is used to avoid the potential problem of Dutile to Brittle Transition Temperature (DBTT) shift of the irradiated ferritic steel structure. Third, it is used to keep the thermal contacting medium lithium in molten state during operation.

\section{DESIGN DESCRIPTION}

The pressurized tubes radial plate design is illustrated in Fig. 1. This design supports the full $1500 \mathrm{MW}$ (thermal) operation at a maximum surface wall loading of $0.40 \mathrm{MW} / \mathrm{m}^{2}$. It consists of approximately 2000 steel-shelled modules with nominal radial dimensions of $60 \mathrm{~cm}$ and toroidal widths of $3.3 \mathrm{~cm}$ (inboard) and $7.1 \mathrm{~cm}$ (outhoard) at the midplane of the reactor. They are combined into subassembly bundles of about 30 modules each. Each module is filled with stagnant low-pressure liquid lithium that serves as a neutron breeder and thermal transfer medium and leak detection medium, as shown in Fig. 1 . Three coolant tubes run poloidally through the static lithium bath. Helium gas at $180 \mathrm{MPa}$ is circulated through 1.5 to $3.5 \mathrm{~cm}$ diameter tubes embedded into the radially oriented plates. These tubes are subjected to maximum primary and secondary stresses of 115 and $230 \mathrm{MPa}$, respectively, which are within the corresponding ASME code allowable design limits of 115 and $345 \mathrm{MPa}$ for the selected material 9Cr-1Mo ferritic steel structural material at $450^{\circ} \mathrm{C}$.

\section{Design Input and Output Parameters}

This high gas pressure operation, a key feature of the design, permits high heat transfer coefficients in the range of 7000 to $8000 \mathrm{~W} / \mathrm{m}^{2} \mathrm{~K}$, and minimizes the helium loop pumping power to $63 \mathrm{MW}$ and void fractions of $7 \%$ and $10.2 \%$ for the inboard and outboard blankets, respectively. For a $60 \mathrm{~cm}$ thick shield/blanket, this corresponds to an additional inboard radial thickness of $4 \mathrm{~cm}$. 2-D finite element method was used to further evaluate the temperature and structural design. The results are similar to the 1-D calculations as shown in Table 1. As shown in Fig. 1, the U-shape coolant tubes can he single wall tubes. In the unlikely event of helium leakage, the leaked helium can be detected Uhrough the lithium bath which is opened to a free surface at the top of the machine. This free surface will be covered by inert gas. The second option of this coolant tube design is to use coaxial tubes. The outer wall of the coaxial tube serves as a redundant helium leakage barrier. The annular tube gap can be filled with stagnant liquid lithium or sodium for heat transfer and leak detection. A double-walled manifold is installed at the top of each module to reduce the number of tubes that must penetrate the vacuum vessel wall. The shell, tubes and manifolds are made from $9 \mathrm{Cr}$-1Mo ferritic steel because of its superior strength, good heat transfer, and radiation tolerance characteristics. However, stainless steel and V-alloy are possible alternatives. For stainless steel, the design window in terms of design margins will he narrower and due to its lower thermal conductivity, high heat transfer coefficient will be needed which can lead to higher pumping power. For V-alloy, due to its higher temperature and strength capabilities, the design window is actually larger than ferritic steel. However, the potential concerns of the reaction of impurities like oxygen and hydrogen in the helium stream interacting with $V$-alloy will have to be addressed by coolant chemistry control. Details of the thermal hydraulic results of the ferritic steel design are presented in [1].

TABLE 1

\section{KEY DESIGN INPUT AND OUTPUT PARAMETERS}

\begin{tabular}{|c|c|}
\hline \multicolumn{2}{|l|}{ - Innuts: } \\
\hline - Total thermal power & $1500 \mathrm{MW}$ \\
\hline \multicolumn{2}{|l|}{ - Neutron wall loading } \\
\hline$\star$ Maximum & $1.8 \mathrm{MW} / \mathrm{m}^{2}$ \\
\hline$\star$ Minimum & $0.9 \mathrm{MW} / \mathrm{m}^{2}$ \\
\hline \multicolumn{2}{|l|}{ - Surface loading } \\
\hline$\star$ Maximum & $0.4 \mathrm{MW} / \mathrm{m}^{2}$ \\
\hline$\star$ Minimum & $0.2 \mathrm{MW} / \mathrm{m}^{2}$ \\
\hline - Helium coolant pressure & $18 \mathrm{MPa}$ \\
\hline - Helium blanket inlet temperature & $270^{\circ} \mathrm{C}$ \\
\hline - Structural material for module and tuhes & $\begin{array}{l}9 \mathrm{Cr}-1 \mathrm{Mo} \\
\text { ferritic steel }\end{array}$ \\
\hline - Minimum first wall thickness & $5 \mathrm{~mm}$ \\
\hline \multicolumn{2}{|l|}{ - Qutputs } \\
\hline - Inboard helium void fraction & $7 \%$ \\
\hline - Outboard helium void fraction & $10.2 \%$ \\
\hline - Maximum first wall temperature & $573^{\circ} \mathrm{C}$ \\
\hline - Minimum first wall temperature & $373^{\circ} \mathrm{C}$ \\
\hline - Maximum pressure tube temperature & $470^{\circ} \mathrm{C}$ \\
\hline - Maximum unstressed structure temperature & $531^{\circ} \mathrm{C}$ \\
\hline - Minimum lithium temperature & $334^{\circ} \mathrm{C}$ \\
\hline - Helium loop pumping power & $63 \mathrm{MW}$ \\
\hline
\end{tabular}




\section{LEAK DETECTION AND PROPAGATION}

Helium will not leak unless there is a physical hole or crack (i.e., material discontinuity) through the tube wall. Diffusion of helium through the material is not an issue. By design, there will be no through holes in the tubes prior to service because full leak testing and advanced nondestructive examination will be carried out at all stages of manufacture and assembly. The only source of a leak would be by the generation of a through crack during service. For the inodule configuration proposed, inspection techniques are available with the capability of detecting axial and circumferential nonthrough flaws of $0.1 \mathrm{~mm}$ in the welds and base metal of tubes and components. These techniques can be used on a volumetric basis during manufacture and assembly of the modules.

Conservative assumptions were made in the calculations of crack propagation in the $9 \mathrm{Cr}-1 \mathrm{Mo}$ material. They are: crack growth characteristics for irradiated to displacement per atom (dpa) levels higher than those expected in I'TER were used [3], for leak-before-hreak analysis, a value of lower shelf fracture toughness, $\mathrm{K}_{\mathrm{IC}}$ reduced by irradiation to $40 \mathrm{MPa}$ $\mathrm{m}^{1 / 2}$ at $100^{\circ} \mathrm{C}$ was used [4]. No threshold $\mathrm{K}_{\mathrm{IC}}$ was used; i.c., crack growth was assumed to occur even at very low stress levels. Crack growth calculations were also used to estimate the size of an initial flaw that would have to be detected if no undetected flaw is to propagate through the cooling tube wall to leakage or tube hurst during the operating life of the blanket cooling system. Analyses using the as-calculated stresses show that an initial flaw depth of $>1.6 \mathrm{~mm}$ (easily detectable) would have to be present to cause leakage in 100,000 cycles. For helium tubes using as-calculated stresses, the analyses also show that the tubes will leak before burst (i.e., leak-before-break). For the unlikely event of coolant leakage, such leakage would be picked up by the monitoring system and allow an orderly shutdown of the reactor.

\section{MAINTENANCE, INSTALLATION, AND REMOVAL OF BUNDLES}

The space allocation for two inboard shield/blanket bundles is shown in Figs. 2 and 3. The gas ieeds and other service connections are all made at the top of the module. This also illustrates why small diameter, high pressure, supply, and return lines are important for this application. For the inner bundles, both are trapped by the TF coils when in operating position. However, the bundles can be removed once the outboard bundles are removed. The first inner bundle can be moved radially out and lifted vertically through the access port. The second inner bundle is then moved radially out until enough clearance gap exists for the service risers plus the width of the bundle. The entire bundle is then transferred sideways and withdrawn with a vertical lift.

\section{HELIUM COOLED ITER DIVERTOR}

To complement the shield/blanket design, we considered the cooling of the ITER divertor. We found that a robust

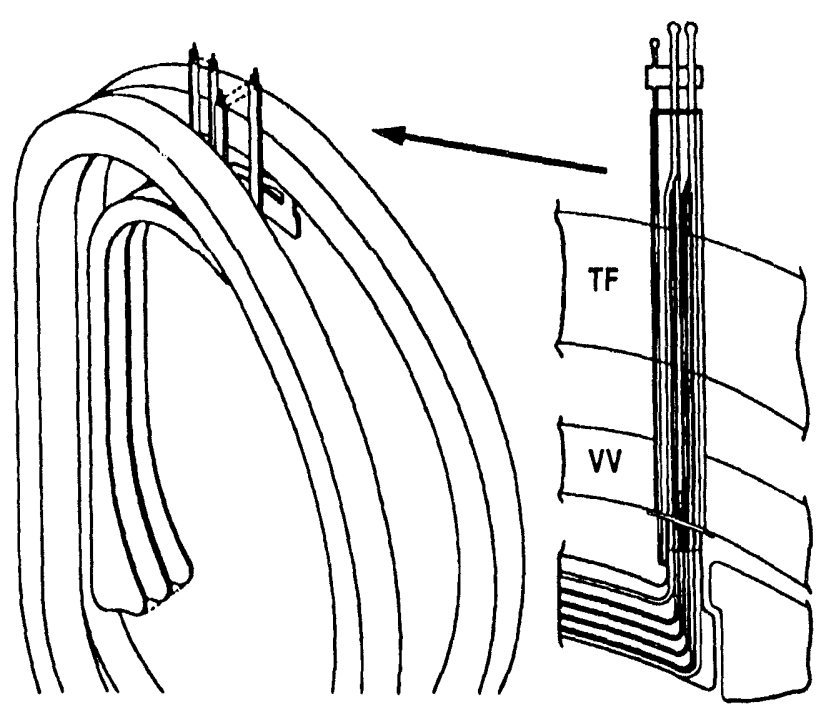

Fig. 2. Shield/blanket module - all pressure welds are far removed from the neutrons.

design for the ITER divertor, based upon present design criteria, can be obtained by using helium cooling at high pressure with an acceptable pumping power fraction of $4 \%$. The following parameters were used for this study:
- Peak heat flux
$5 \mathrm{MW} / \mathrm{m}^{2}$
- Armor material
$5 \mathrm{~mm}$ thick Be
- Structural material
DS-Cu

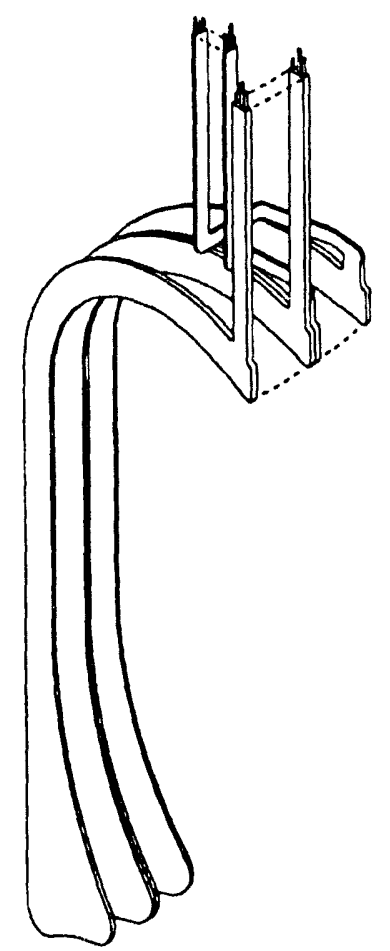

Fig. 3. Two inboard shield bundles, one located under and one located between the TF coils. 
- Coolant channel

$\begin{array}{ll}\text { - Diameter } & 16 \mathrm{~mm} \\ \text { - Pitch } & 20 \mathrm{~mm} \\ \text { Inlet coolant temperature } & 300^{\circ} \mathrm{C}\end{array}$

In this analysis, helium pressure of $18 \mathrm{MPa}$ was assumed. For a simple heat transfer surface design, using smooth channels, the following results are obtained:

- Helium flow rate per $\mathrm{m}^{2}$ of $23 \mathrm{~kg} / \mathrm{sec}$ divertor area

- Pressure drop

$0.13 \mathrm{MPa}$

- Heat transfer coefficient

$20,000 \mathrm{~W} / \mathrm{m}^{2} \mathrm{~K}$

- Pumping power per $\mathrm{m}^{2}$ of divertor surface

$0.2 \mathrm{MW}$

- Peak surface temperature $790^{\circ} \mathrm{C}$ of $\mathrm{Be}$

The performance can be improved significantly by roughening the part of the coolant channel with maximum heat flux. Roughening increases the heat transfer coefficient by a factor of 1.8 and the friction factor by a factor of 4 at given Reynolds number. The net result is a smaller flow rate and smaller pumping power. If $50 \%$ of the flow channel is roughened, the pumping power requirements will be reduced by about $50 \%$. In addition to roughening, there are several other techniques [2] that can be used to improve the heat removal pumping power performance even further. Peak heat fluxes larger than $5 \mathrm{MW} / \mathrm{m}^{2}$ could be handled by using advanced techniques discussed in [2].

\section{SAFETY}

Preliminary safety assessment was performed. The key issues of helium leakage and rapid depressurization of the helium and lithium release in an over-pressurization accident were evaluated. The safety effects from leakage were addressed by the leak-before-break design, and the dynamic forces are limited correspondingly. If needed, structural protection from the jet impingement can be provided. Calculations show that cooling capability is available to remove decay heat under both pressurized and depressurized system conditions. Over pressurization of confinement structure is limited by the available helium inventory and the confinement structure pressure relief. Maximum pressure (without segmentation, relief and isolation) is less than $19 \mathrm{KPa}$. It is concluded that with the design features incorporated, this $18 \mathrm{MPa}$ design can be designed to handle the loss of vacuum and loss of coolant accidents.

\section{BALANCE OF PLANT}

The balance-of-plant and the corresponding critical components in the external helium loop to operate at $18 \mathrm{MPa}$ were reviewed. We found that the requirements are well within present industrial capability and the design could be made modular (to minimize initial capital costs) to allow additional compressor systems to be added as the power level in ITER increases over time. The high gas pressure of this design is not unprecedented in that commercial natural gas systems operate at gas pressure level well above $30 \mathrm{MPa}$. We also found that net power generation is possible by using an energy recovery turbine on the compressor shaft during the extended operation phase of ITER.

\section{CONCLUSIONS}

We considered the design of a helium-cooled shield/blanket for ITER, by setting up relevant design guidelines and by focusing on the questions of helium leakage and reliability. The configuration selected is a pressurized tubes design embedued in radially oriented plates. These plates can be made from stainless steel, ferritic steel or from $\mathrm{V}$-alloy. Helium leakage to the plasma chamber is eliminated by the leak-before-break design which will allow time for leak detection. Proper quality control and inspection programs will be required. No critical issues have been identified which would compromise this design approach and no major R\&D tasks are needed to proceed. The development of $18 \mathrm{MPa}$ helium loop components can be developed within the ITER schedule. This combination of passive safety, minimum risk development, supported by proven industrial record worldwide, and the immediate extension to power producing designs makes the helium cooled blanket design an excellent and viable alternative to promote the success of the ITER program. The helium cooling scheme proposed is fully applicable to heat removal from the divertor system. This shield/blanket concept is also a viable approach to a DEMO or power reactor design.

\section{REFERENCES}

[1] Bourque, R.F., "Thermal-Hydraulic Analysis of a HighPressure Helium-Cooled Shield/Blanket for ITER," to be published in Proc. 15th IEEE/NPSS Symp. on Fusion Engineering.

[2] Baxi, C.B., and The GA Divertor Team, "Evaluation of Helium Cooling For Fusion Divertor," to be published in Proc. IAEA Tech. Com. Mig. on Fusion Reactor Design and Tech.

[3] Gelles, D.S., "Effects of Irradiation on Ferritic Alloys and Implications for Fusion Reactor Applications," J. Nucl. Mater. 149 (1987) 192; and private communication from A. Rowcliffe of ORNL.

14] Lucas, G.E., and D.S. Gelles, "The Influence of Irradiation on Fracture and Impact Properties of Fusion Reactor Materials," J. Nucl. Mater. $155-157$ (1988) 164; and private communication from $A$. Rowcliffe of ORNL. 



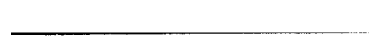

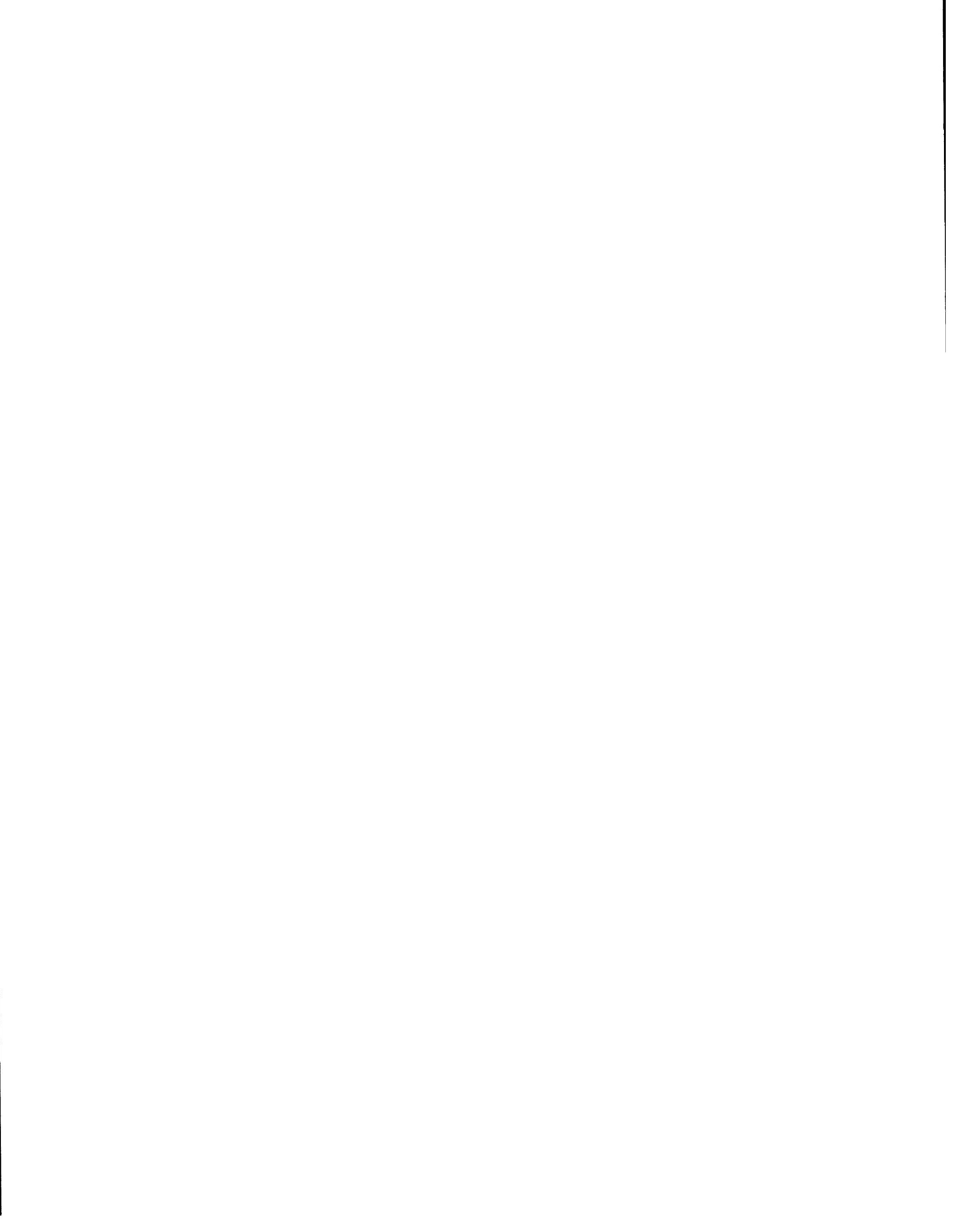

